Cochrane Database of Systematic Reviews

\title{
Antibiotics at the time of removal of central venous catheter to reduce morbidity and mortality in newborn infants (Review)
}

McMullan RL, Gordon A

McMullan RL, Gordon A.

Antibiotics at the time of removal of central venous catheter to reduce morbidity and mortality in newborn infants.

Cochrane Database of Systematic Reviews 2018, Issue 3. Art. No.: CD012181.

DOI: 10.1002/14651858.CD012181.pub2.

www.cochranelibrary.com 
TABLE OF CONTENTS

HEADER

ABSTRACT

PLAIN LANGUAGE SUMMARY

SUMMARY OF FINDINGS

BACKGROUND

OBJECTIVES

METHODS

RESULTS

Figure 1.

Figure 2.

Figure 3.

Figure 4.

Figure 5.

Figure 6.

DISCUSSION

AUTHORS' CONCLUSIONS

ACKNOWLEDGEMENTS

REFERENCES

CHARACTERISTICS OF STUDIES

DATA AND ANALYSES

Analysis 1.1. Comparison 1 Cephazolin compared to no cephazolin, Outcome 1 Late-onset blood steam infection.

Analysis 1.2. Comparison 1 Cephazolin compared to no cephazolin, Outcome 2 CLABSI.

Analysis 1.3. Comparison 1 Cephazolin compared to no cephazolin, Outcome $3 \mathrm{Gram}$-positive blood stream infection.

Analysis 1.4. Comparison 1 Cephazolin compared to no cephazolin, Outcome 4 Clinical sepsis. 
[Intervention Review]

\section{Antibiotics at the time of removal of central venous catheter to reduce morbidity and mortality in newborn infants}

Rowena L McMullan¹, Adrienne Gordon ${ }^{1}$

1Neonatology, Royal Prince Alfred Hospital, Sydney, Australia

Contact address: Adrienne Gordon, Neonatology, Royal Prince Alfred Hospital, Sydney, NSW, 2050, Australia.

adrienne.gordon@sydney.edu.au.

Editorial group: Cochrane Neonatal Group.

Publication status and date: New, published in Issue 3, 2018.

Citation: McMullan RL, Gordon A. Antibiotics at the time of removal of central venous catheter to reduce morbidity and mortality in newborn infants. Cochrane Database of Systematic Reviews 2018, Issue 3. Art. No.: CD012181. DOI: 10.1002/14651858.CD012181.pub2.

Copyright @ 2018 The Cochrane Collaboration. Published by John Wiley \& Sons, Ltd.

\section{A B S T R A C T}

\section{Background}

Late-onset sepsis is associated with increased rates of mortality and morbidity in newborn infants, in addition to poorer long-term developmental outcomes and increased length of stay and hospital costs. Central line-associated blood stream infection (CLABSI) is the most common cause of late-onset sepsis in hospitalised infants, and prevention of CLABSI is a key objective in neonatal care. Increased frequency of CLABSI around the time of removal of central venous catheters (CVCs) has been reported, and use of antibiotics at the time of removal may reduce the incidence and impact of late-onset sepsis in vulnerable newborn infants.

\section{Objectives}

To determine the efficacy and safety of giving antibiotics at the time of removal of a central venous catheter (CVC) for reduction of morbidity and mortality in newborn infants, in particular effects on late-onset sepsis.

\section{Search methods}

We used the standard search strategy of the Cochrane Neonatal Review Group without language restriction to search the Cochrane Central Register of Controlled Trials (CENTRAL; 2017, Issue 3), MEDLINE via PubMed (1966 to 6 April 2017), Embase (1980 to 6 April 2017), and the Cumulative Index to Nursing and Allied Health Literature (CINAHL) (1982 to 6 April 2017). We also searched clinical trials databases, conference proceedings, and reference lists of retrieved articles for randomised controlled trials and quasi-randomised trials.

\section{Selection criteria}

Randomised, quasi-randomised, and cluster-randomised trials considering use of any antibiotic or combination of antibiotics at the time of CVC removal in newborn infants compared with placebo, no antibiotics, or another antibiotic or combination of antibiotics.

\section{Data collection and analysis}

We extracted data using standard methods of the Cochrane Neonatal Review Group. Two review authors independently selected, assessed the quality of, and extracted data from the included study.

\section{Main results}

Only one randomised controlled trial was eligible for inclusion in this analysis. Forty-four of a total of 88 infants received two doses of cephazolin at the time of removal of CVC compared with no antibiotics at the time of removal of CVC in the control group. No infant in the intervention group developed late-onset sepsis after CVC removal compared with five of $44(11 \%)$ in the control group (risk ratio (RR) 0.09 , $95 \%$ confidence interval ( $\mathrm{Cl}) 0.01$ to 1.60 ). Cephazolin given at the time of removal of CVC did not statistically significantly alter late-onset 
sepsis rates and led to no significant differences in any of the prespecified outcomes. Review authors judged the study to be of low quality because of high risk of bias and imprecision.

\section{Authors' conclusions}

Randomised controlled trials have provided inadequate evidence for assessment of the efficacy or safety of antibiotics given at the time of CVC removal. The single identified trial was underpowered to address this question. Future research should be directed towards targeting use of antibiotics upon removal of CVC for those at greatest risk of complications from CVC removal-related CLABSI. Researchers should include safety data such as impact upon antibiotic use and resistance patterns. This investigation would best occur as part of a bundle of quality improvement care interventions provided by neonatal networks.

\section{PLAIN LANGUAGE SUMMARY}

\section{Antibiotics at the time of removal of a central line to reduce complications in newborn infants}

\section{Review question}

Does giving antibiotics at the time of removal of a central line reduce death and other serious complications in newborn infants?

\section{Background}

Central lines are specialised catheters that are inserted into a vein so that the tip of the catheter lies in the central veins close to the heart. Central lines are necessary to provide life-saving medications and nutrition to sick babies. However, their use is sometimes associated with complications, and infection is one of the most common and important of these. It has been noted in some studies that infections occur as central lines are being removed, and it is hypothesised that giving antibiotics as the central line is removed may help prevent infection and associated complications.

\section{Study characteristics}

We found only one small trial of low quality that considered antibiotics at the time of removal of a central line.

\section{Key results}

Researchers found no significant differences in complication rates between babies who were and were not given antibiotics.

\section{Conclusion}

At present, review authors have not found enough evidence to recommend giving antibiotics at the time of removal of a central line to prevent complications in newborn babies. 


\section{SUMMARY OF FINDINGS}

Summary of findings for the main comparison. Antibiotics on removal of central venous catheter compared with no antibiotics

Cephazolin compared with no cephazolin in newborn infants

Patient or population: newborn infants undergoing removal of central venous catheter

Settings: neonatal intensive care

Intervention: cephazolin

Comparison: no cephazolin

\begin{tabular}{|c|c|c|c|c|c|c|}
\hline \multirow[t]{2}{*}{ Outcomes } & \multicolumn{2}{|c|}{ Illustrative comparative risks $(95 \% \mathrm{Cl})$} & \multirow{2}{*}{$\begin{array}{l}\text { Relative effect } \\
(95 \% \mathrm{Cl})\end{array}$} & \multirow{2}{*}{$\begin{array}{l}\text { No. of partici- } \\
\text { pants } \\
\text { (studies) }\end{array}$} & \multirow{2}{*}{$\begin{array}{l}\text { Quality of the } \\
\text { evidence } \\
\text { (GRADE) }\end{array}$} & \multirow[t]{2}{*}{ Comments } \\
\hline & Assumed risk & Corresponding risk & & & & \\
\hline \multirow{4}{*}{$\begin{array}{l}\text { Late-onset blood steam in- } \\
\text { fection }\end{array}$} & \multicolumn{2}{|c|}{ Study population } & \multirow{4}{*}{$\begin{array}{l}\mathbf{R R} 0.09 \\
(0.01 \text { to } 1.6)\end{array}$} & \multirow{4}{*}{$\begin{array}{l}88 \\
\text { (1 study) }\end{array}$} & \multirow{4}{*}{$\begin{array}{l}\oplus \oplus \ominus \ominus \\
\text { lowa,b }\end{array}$} & \\
\hline & 114 per 1000 & $\begin{array}{l}10 \text { per } 1000 \\
\text { (1 to } 182)\end{array}$ & & & & \\
\hline & \multicolumn{2}{|l|}{ Moderate } & & & & \\
\hline & 114 per 1000 & $\begin{array}{l}10 \text { per } 1000 \\
\text { (1 to } 182)\end{array}$ & & & & \\
\hline \multirow[t]{2}{*}{ Neonatal mortality } & \multicolumn{2}{|c|}{ Study population } & \multirow[t]{2}{*}{ Not estimable } & \multirow{2}{*}{$\begin{array}{l}88 \\
\text { (1 study) }\end{array}$} & \multirow{2}{*}{$\begin{array}{l}\oplus \oplus \ominus \ominus \\
\text { low } w^{a, c}\end{array}$} & \\
\hline & \multicolumn{2}{|l|}{ Moderate } & & & & \\
\hline \multirow{3}{*}{$\begin{array}{l}\text { All-cause mortality before } \\
\text { hospital discharge }\end{array}$} & \multicolumn{2}{|c|}{ Study population } & \multirow[t]{3}{*}{ Not estimable } & \multirow{3}{*}{$\begin{array}{l}88 \\
\text { (1 study) }\end{array}$} & \multirow{3}{*}{$\begin{array}{l}\oplus \oplus \oplus \ominus \\
\text { lowa,c }\end{array}$} & \\
\hline & See comment. & See comment. & & & & \\
\hline & \multicolumn{2}{|l|}{ Moderate } & & & & \\
\hline
\end{tabular}




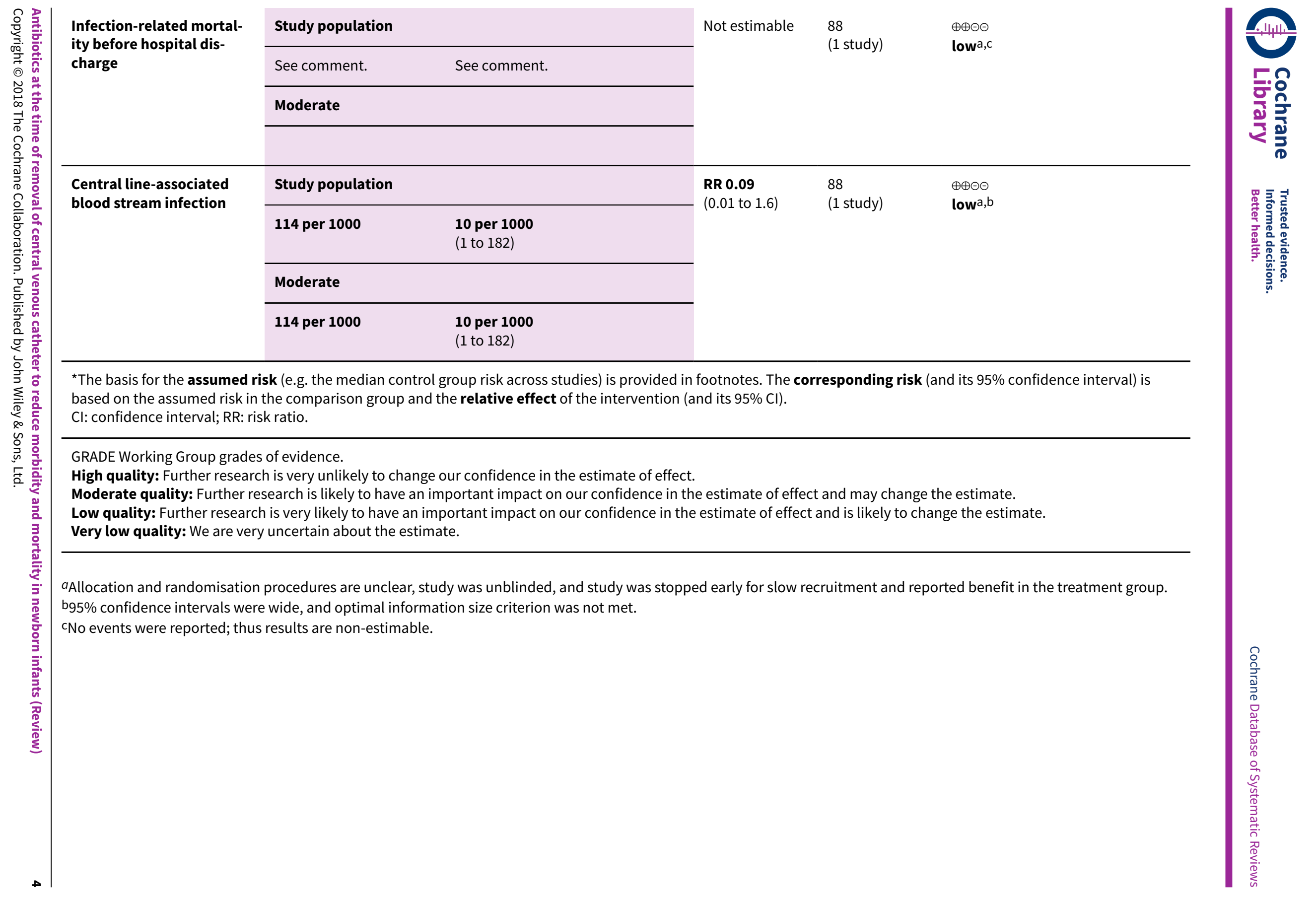




\section{B A C K G R O U N D}

Central venous catheters (CVCs) are used regularly in the neonatal intensive care unit (NICU) to provide safe, stable venous access for sick newborn infants. They provide nutrition that is critical for growth when infants do not tolerate enteral feeds, as well as a portal for other necessary intravenous fluids and medications that cannot be safely infused via a peripheral venous cannula. Central venous catheters avoid repeated painful procedures that are associated with multiple peripheral cannulas (Ainsworth 2015; Janes 2000). However, their use is associated with various complications.

\section{Description of the condition}

One of the most important complications associated with use of a CVC is central line-associated blood stream infection (CLABSI). The Centers for Disease Control and Prevention (CDC) defines a CLABSI as "a primary blood stream infection in a patient that had a central line within the 48-hour period before the development of the blood stream infection, and is not related to an infection at another site" (O'Grady 2011). The incidence of CLABSI varies with the population studied but most recently is reported as 1.1 to 3.0 per 1000 central line days in NICUs in high-income countries (Bowen 2017; Canadian Neonatal Network 2015; Dudeck 2015; RCPCH 2016). Incidence and impact are considerably higher in low- and middle-income settings, with metaanalysis reporting rates of 10.2 to 60 per 1000 central line days (Allegranzi 2011). Central line-associated blood stream infection usually occurs via skin commensals that migrate through the catheter entry site or cannula hub (Salzman 1993). Coagulasenegative staphylococcus (CoNS) is the predominant pathogen in high-income countries (Salzman 1995). Central line-associated blood stream infection in low- and middle-income countries is more likely to be caused by Gram-negative or antibiotic-resistant organisms (Rosenthal 2010; The Joint Commission 2012) and leads to increased mortality compared with CLABSI in high-income countries (Rosenthal 2009). Although the mortality associated with CoNS infection is low (Isaacs 2003; Karlowicz 2000), the impact of CoNS on both an individual and an organisational level remains high. Coagulase-negative staphylococcus sepsis is associated with significant morbidity in very low birth weight infants (Gray 1995; Makhoul 2005) and is associated with prolonged hospital stay and associated increased hospital costs (Gray 1995). Coagulasenegative staphylococcus infection in preterm infants has been shown to be associated with increased risk of neurodevelopmental impairment at preschool age (Alshaikh 2014).

Fortunately, CLABSI has been shown to be highly modifiable with 'bundles' of healthcare interventions. A bundle is defined as "a limited number of specific practices, each essential for effective and safe patient care and that, when implemented together, result in additional improvements in patient outcomes" (Pronovost 2006). These multi-disciplinary, evidence-based best practice recommendations are effective in reducing CLABSI in the NICU (Bizzarro 2010; McMullan 2016; Schulman 2011). In many settings, use of these bundles has led to reduced rates of CLABSI, in particular by improving hand hygiene and adherence to catheter insertion and maintenance protocols. However, late-onset sepsis remains a significant challenge for infants in the NICU, particularly for the smallest and most preterm infants, and interventions that are simple and may offer further reduction in CLABSI rates need to be explored. All-cause late-onset sepsis is an important and potentially modifiable risk factor for increased mortality, poor growth, and poor neurodevelopmental outcomes in early childhood (Schlapbach 2011; Stoll 2002; Stoll 2004).

\section{Description of the intervention}

CVCs are prone to colonisation, which usually occurs from extraluminal or intraluminal contamination. The patient's own flora may directly migrate along the outside of the CVC at the entry site, resulting in colonisation at the catheter tip (Mermel 2011). Intraluminal colonisation results from invasion at access points, such as the catheter hub, and tends to occur in lines with prolonged dwell times (Mermel 2011; Salzman 1993). These organisms, once adherent to the CVC, produce a biofilm that allows them to 'hide' from host defences. CLABSI occurs when single organisms or clumps of biofilm dislodge, enter the bloodstream, and multiply. Prophylactic antibiotics used for the duration of the life of the central line are associated with a reduction in proven and suspected sepsis but are not recommended because of lack of evidence of longer-term benefits and concerns about the selection of antibiotic-resistant organisms (Jardine 2008).

\section{How the intervention might work}

It is hypothesised that the biofilm that develops on the catheter surface is stripped off during removal of the CVC, causing bacteria to 'shower' into the bloodstream (van den Hoogen 2008). The effect of this on the individual depends on several factors, including pathogenicity, load, and rate of multiplication of the organism, as well as integrity of the host immune system. Cases of cultureproven sepsis occur up to seven days after CVC removal, with $23 \%$ of cases of CLABSI occurring within 72 hours after catheter removal (van den Hoogen 2008). Antibiotics given at the time of CVC removal may therefore reduce the effect of the 'shower' of bacteria causing late-onset sepsis, particularly in the most vulnerable infants, and have reduced the incidence of CLABSI in observational studies (Lindquist 2016; van den Hoogen 2008), but concerns about potential side effects are ongoing. Antibiotic resistance has emerged as an important and urgent issue globally, and decreasing antibiotic use is a matter of priority. Awareness of the importance of the microbiome in maintaining health is increasing, as is knowledge of the detrimental effects that antibiotics may exert upon an infant's normal flora. The impact of CVC removal upon the microbiome or upon antibiotic resistance at the time of CVC removal has not been explored in the literature.

\section{Why it is important to do this review}

Reducing the frequency of late-onset sepsis, particularly in the very low birth weight infant, may have a significant impact on the health of the newborn and may decrease hospital admission times and associated hospital costs. At present no systematic reviews have examined antibiotics given at the time of CVC removal.

\section{OBJECTIVES}

To determine the efficacy and safety of giving antibiotics at the time of removal of a central venous catheter (CVC) for reduction of morbidity and mortality in newborn infants, in particular effects on late-onset sepsis. 


\section{METHODS}

\section{Criteria for considering studies for this review}

\section{Types of studies}

We considered randomised, quasi-randomised, and clusterrandomised controlled clinical trials.

\section{Types of participants}

Newborn infants admitted in a healthcare setting, undergoing removal of a CVC. A newborn infant was defined as an infant aged up to and including 28 days' corrected gestational age. We applied no restrictions on gestation or weight at the time of birth. A CVC was defined as a venous catheter inserted in such a way that the line tip is placed into a large central venous vessel. This includes CVCS inserted via peripheral veins, umbilical veins, and central veins.

\section{Types of interventions}

We included the following interventions.

- Any antibiotic or combination of antibiotics given at the time of removal of a CVC compared with placebo.

- Any antibiotic or combination of antibiotics given at the time of removal of a CVC compared with no antibiotics.

- Any antibiotic or combination of antibiotics given at the time of removal of a CVC compared with another antibiotic or a different combination of antibiotics.

We considered all antibiotics given within 24 hours of CVC removal, at any dose and any regimen. We excluded trials comparing prophylactic antibiotics given for the duration of the CVC, as this is the topic of a separate review (Jardine 2008).

\section{Types of outcome measures}

\section{Primary outcomes}

- Incidence of any late-onset blood stream infection after catheter removal: defined as bacteraemia with at least one positive blood culture in an infant who has had a previous CVC removal plus clinical and/or laboratory manifestations of infection

- Neonatal mortality

\section{Secondary outcomes}

- All-cause mortality before hospital discharge

- Infection-related mortality before hospital discharge

- Central line-associated blood stream infection (CLABSI): defined as bacteraemia in an infant with a CVC removed within the previous 48 hours with at least one positive blood culture, clinical manifestations of infection, and no apparent source for the blood stream infection other than the catheter

- Proven infection with a Gram-positive organism after catheter removal: defined as bacteraemia with at least one positive blood culture of a Gram-positive organism in an infant who has had a previous CVC removal plus clinical and/or laboratory manifestations of infection

- Proven infection with a Gram-negative organism after catheter removal: defined as bacteraemia with at least one positive blood culture of a Gram-negative organism in an infant who has had a previous CVC removal plus clinical and/or laboratory manifestations of infection
- Proven infection after catheter removal with a fungus: defined as bacteraemia with at least one positive blood culture of a fungus in an infant who has had a previous CVC removal plus clinical and/or laboratory manifestations of infection

- Clinical sepsis after catheter removal: defined as a clinical picture of sepsis with no confirmatory blood markers or cultures in an infant who has had a previous CVC removal

- Chronic lung disease (oxygen requirement at 36 weeks' postmenstrual age)

- Duration of ventilation (hours or days)

- Duration of respiratory support (hours or days)

- Duration of hospital stay (days)

- Neurodevelopmental outcome (validated scales of neurodevelopment at 12 months of age or later)

\section{Search methods for identification of studies}

\section{Electronic searches}

We used criteria and standard methods of Cochrane and the Cochrane Neonatal Review Group (see the Cochrane Neonatal Group search strategy for specialized register).

We conducted a comprehensive search including the Cochrane Central Register of Controlled Trials (CENTRAL; 2016, Issue 6) in the Cochrane Library; MEDLINE via PubMed (1966 to 6 April 2017); Embase (1980 to 6 April 2017); and the Cumulative Index to Nursing and Allied Health Literature (CINAHL) (1982 to 6 April 2017), using the following search terms: ((central AND (catheter* OR cannul ${ }^{\star}$ OR line OR vein OR venous)) OR CVC OR CVL OR central vein catheter OR central vein line OR central venous line OR central line OR central catheter OR PICC) AND (antibiotic*), plus database-specific limiters for randomised controlled trials (RCTs) and neonates (see Appendix 1 for the full search strategies for each database). We did not apply language restrictions.

We searched clinical trials registries for ongoing and recently completed trials (clinicaltrials.gov; the World Health Organization International Trials Registry and Platform - www.whoint/ictrp/ search/en/; the ISRCTN Registry) and the Hong Kong clinical trials register (www.hkclinicaltrials.com).

\section{Searching other resources}

We also searched for relevant trials from conferences and symposia proceedings of the Perinatal Society of Australia and New Zealand and the Pediatric Academic Societies (American Pediatric Society, Society for Pediatric Research, and European Society for Pediatric Research) from 1990 to the present. Both review authors independently screened identified articles to check eligibility for inclusion in the review and managed disagreement through discussion until consensus was achieved.

\section{Data collection and analysis}

We used the methods of the Cochrane Neonatal Review Group for data collection and analysis.

\section{Selection of studies}

The review authors separately assessed relevant titles for inclusion in the review, using a specifically designed eligibility checklist. We excluded irrelevant trials and retrieved the full text of potentially eligible trials. We resolved discrepancies through discussion until 
consensus was achieved. For full-text articles reviewed, we noted reasons for inclusion and exclusion.

\section{Data extraction and management}

The review authors independently extracted data from the fulltext articles of included studies, using a specifically designed data sheet. We contacted trial authors when further information was required. We met to cross-check information and resolved disagreements through discussion. One review author (RM) entered trial data into Review Manager 5 software (Review Manager 2014), and the other (AG) cross-checked trial data against her own data.

\section{Assessment of risk of bias in included studies}

Two review authors (RM and AG) independently assessed the risk of bias (low, high, or unclear) of all included trials, using the Cochrane 'Risk of bias' tool (Higgins 2011) for the following domains.

- Sequence generation (selection bias).

- Allocation concealment (selection bias).

- Blinding of participants and personnel (performance bias).

- Blinding of outcome assessment (detection bias).

- Incomplete outcome data (attrition bias).

- Selective reporting (reporting bias).

- Any other bias.

We resolved disagreements by discussion. See Appendix 2 for a more detailed description of risk of bias for each domain.

\section{Measures of treatment effect}

We used standard methods of the Cochrane Neonatal Review Group to analyse trial data.

We performed statistical analyses using Review Manager 5 software (Review Manager 2014). We analysed categorical data using risk ratios (RRs) and risk differences (RDs). For statistically significant outcomes, we intended to calculate number needed to treat for an additional beneficial (NNTB) or harmful (NNTH) outcome. No continuous data were available for analysis.

\section{Unit of analysis issues}

The intended unit of analysis was the individual infant. We planned to use data from each infant once only, even if the patient had multiple lines, but we did not do this for this review. We intended to include cluster-randomised trials if they met inclusion criteria.

\section{Dealing with missing data}

We contacted the authors of the included study to request additional information and clarification. Some data remain missing, as described in Selective reporting (reporting bias) and Secondary outcomes.

\section{Assessment of heterogeneity}

We planned to assess extent of heterogeneity by using the $1^{2}$ statistic to examine the percentage of total variation across studies due to heterogeneity rather than to chance. We will grade the degree of heterogeneity as follows: < $25 \%$ none, $25 \%$ to $49 \%$ low, $50 \%$ to $74 \%$ moderate, and $>75 \%$ high heterogeneity. If we identified substantial heterogeneity, we planned to explore this by performing prespecified subgroup and sensitivity analyses.

\section{Assessment of reporting biases}

If we identified a sufficient number of studies $(>10)$, we intended to enter data from all included studies into a funnel plot (trial effect against trial size) in an attempt to investigate the likelihood of overt publication bias. We contacted trial authors to ask them to provide missing outcome data.

\section{Data synthesis}

We performed statistical analysis using Review Manager 5 software (Review Manager 2014). We used a fixed-effect model inverse variance meta-analysis for all analyses. We planned to investigate the possible source of heterogeneity by performing subgroup and sensitivity analyses.

\section{Quality of evidence}

We used the GRADE approach, as outlined in the GRADE Handbook (Schünemann 2013), to assess the quality of evidence for the following (clinically relevant) outcomes.

- Incidence of any late-onset blood stream infection after catheter removal: defined as bacteraemia with at least one positive blood culture in an infant who has had previous CVC removal plus clinical and/or laboratory manifestations of infection.

- Neonatal mortality.

- All-cause mortality before hospital discharge.

- Infection-related mortality before hospital discharge.

- Central line-associated blood stream infection (CLABSI): defined as bacteraemia in an infant who has had CVC removal within the previous 48 hours with at least one positive blood culture, clinical manifestations of infection, and no apparent source for the blood stream infection other than the catheter.

Two review authors independently assessed the quality of evidence for each of the outcomes above. We considered evidence from RCTs as high quality but downgraded the evidence one level for serious (or two levels for very serious) limitations based on the following: design (risk of bias), consistency across studies, directness of evidence, precision of estimates, and presence of publication bias. We used the GDT Guideline Development Tool (GRADEpro GDT) to create Summary of findings for the main comparison to report the quality of evidence.

The GRADE approach yields an assessment of the quality of a body of evidence according to one of four grades.

- High: We are very confident that the true effect lies close to that of the estimate of the effect.

- Moderate: We are moderately confident in the effect estimate: The true effect is likely to be close to the estimate of the effect, but there is a possibility that it is substantially different.

- Low: Our confidence in the effect estimate is limited: The true effect may be substantially different from the estimate of the effect.

- Very low: We have very little confidence in the effect estimate: The true effect is likely to be substantially different from the estimate of effect.

\section{Subgroup analysis and investigation of heterogeneity}

Provided that sufficient data were available, we planned the following subgroup analyses. 
- Term ( $\geq 37$ weeks' gestation) versus preterm (<37 weeks) infants.

- Very low birth weight (<1500 grams) versus birth weight $\geq 1500$ grams.

- Low- and middle-income settings versus high-income settings as defined by the World Bank (World Bank Data Resource 2015).

- Type of antibiotic: broad spectrum (defined as an antibiotic with activity against multiple organisms) versus narrow spectrum (defined as an antibiotic primarily aimed at a specific organism).

- Type of catheter: single-lumen versus multiple-lumen, centrally inserted catheters versus peripherally inserted central venous catheters versus umbilical catheters.

\section{Sensitivity analysis}

We planned to explore methodological heterogeneity by performing sensitivity analyses. We planned to perform sensitivity analyses by excluding trials of lower quality, identified by lack of any of the following: allocation concealment, adequate randomisation, blinding of treatment, or greater than $10 \%$ loss to follow-up.

\section{RE S U L T S}

\section{Description of studies}

We included one study that met inclusion criteria - Hemels 2011 (Figure 1). We identified no ongoing studies. 
Figure 1. Study flow diagram.

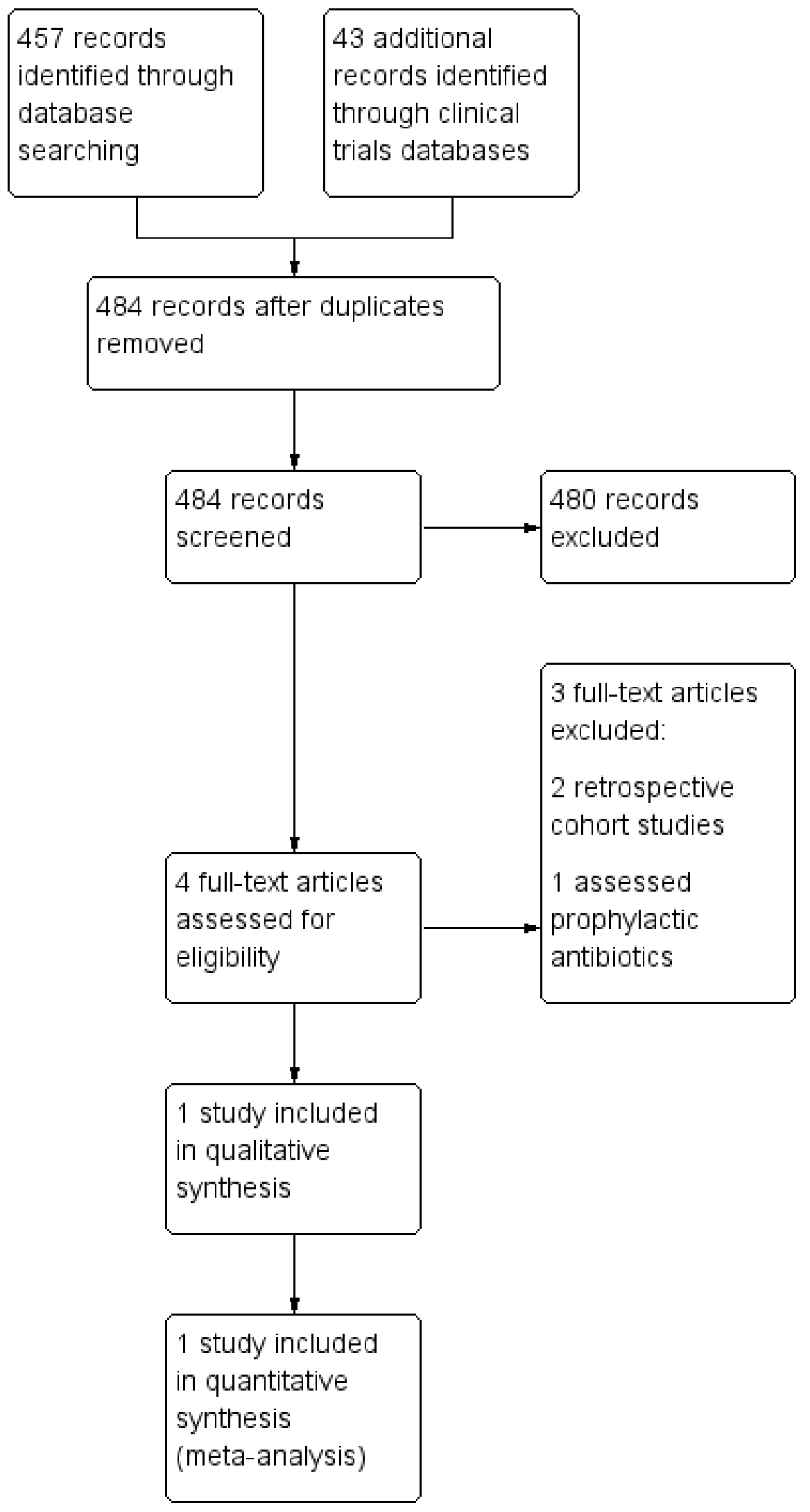




\section{Results of the search}

We obtained the full text of four studies for review. One RCT met our criteria for inclusion (Hemels 2011). See Characteristics of included studies and Characteristics of excluded studies.

\section{Included studies}

Hemels 2011 studied 88 infants at less than 37 weeks' corrected gestational age with a percutaneous central venous catheter (PCVC) in situ. Infants already receiving antibiotics or having a PCVC removed owing to phlebitis or clinical sepsis were excluded. Investigators randomised infants to no antibiotics or two doses of intravenous cephazolin at $50 \mathrm{mg} / \mathrm{kg}$ one hour before and 12 hours after removal of a PCVC. The primary outcome was sepsis within 48 hours of PCVC removal; sepsis was defined as clinical signs of sepsis accompanied by laboratory abnormalities and a positive blood culture. Other outcomes were C-reactive protein (CRP) value at 24,48 , and 72 hours after removal, hospitalisation days, and ventilation days. Mortality was a prespecified outcome that was not reported.

Data show no significant differences in clinical characteristics between groups. Trial authors reported a statistically significant reduction in sepsis within 48 hours of PCVC removal in their intervention group ( $0 \%$ in the intervention group vs $11 \%$ in the control group) and reported no other statistical differences in any of their prespecified outcomes. The trial was stopped early (at 88 of 220 planned participants) owing to slow recruitment and a reported significant reduction in sepsis in the group of infants receiving cefazolin during removal of a PCVC on interim analysis.

\section{Excluded studies}

During our search, we identified no other RCTs that met our inclusion criteria. We reviewed and excluded three full-text articles, as two were retrospective cohort analyses and one was a randomised controlled trial of prophylactic antibiotics given during the life of the CVC, rather than just at removal.

\section{Risk of bias in included studies}

We considered the single included study to be at high risk of bias, as it reported unclear randomisation and allocation procedures, was unblinded, and was stopped early owing to slow recruitment. We presented ratings of methodological quality in the Characteristics of included studies table and summarised them in Figure 2.

\section{Figure 2. Risk of bias graph: review authors' judgements about each risk of bias item presented as percentages across all included studies.}

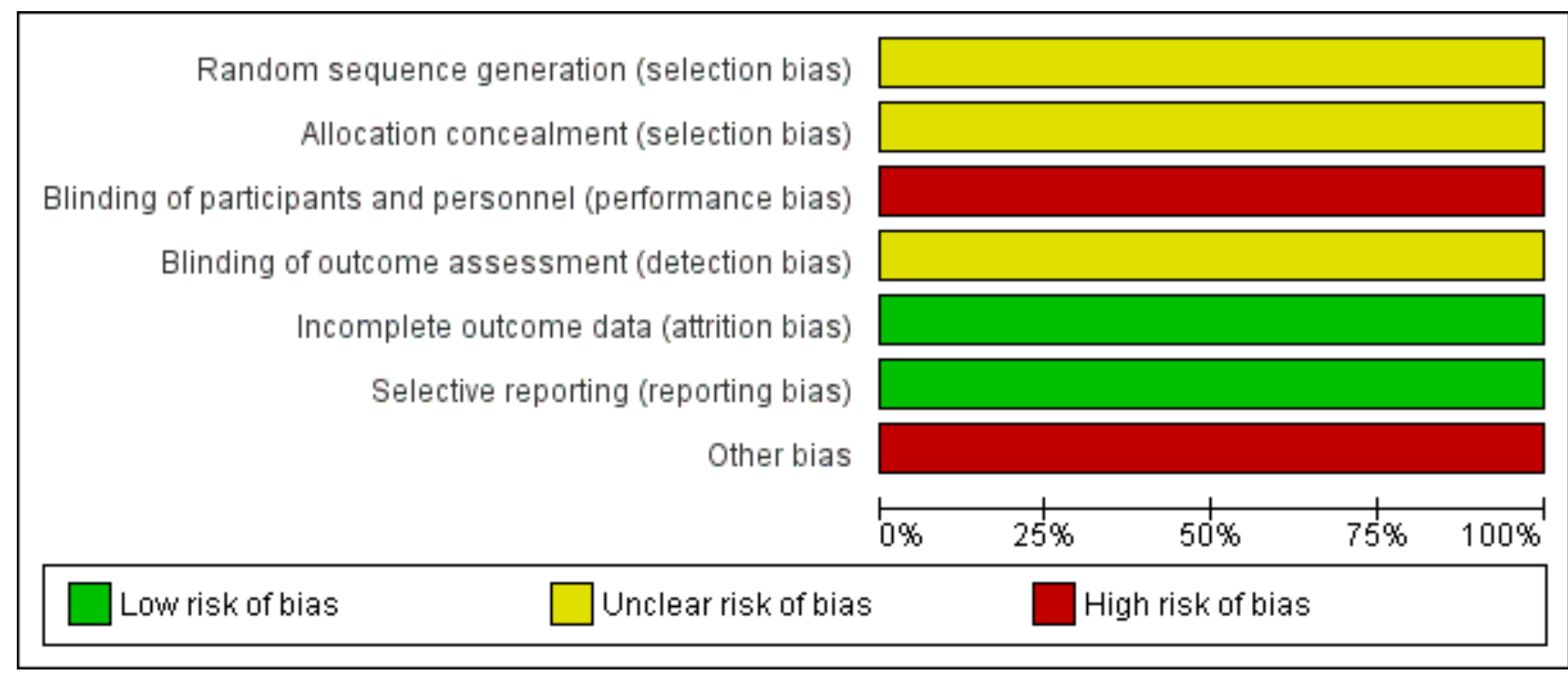

\section{Allocation}

Trial authors did not report randomisation and allocation procedures.

\section{Blinding}

Hemels 2011 did not attempt to blind caregivers, families, or investigators to the intervention. Investigators provided no information on whether outcome assessors were blinded. In this study, participants in the intervention group would require a peripheral intravenous cannula to administer the antibiotic; thus intervention group infants would be clearly identifiable. However, owing to the nature of the intervention, performance bias is unlikely, as the intervention is well defined and guidelines surrounding medication administration are such that performance would be unlikely to be affected.

\section{Incomplete outcome data}

Outcome data were available for all infants entering this study.

\section{Selective reporting}

Hemels 2011 did not report mortality, although this was a prespecified outcome. On contacting trial authors, we were able to ascertain these data.

\section{Other potential sources of bias}

This trial was stopped early (at 88 of 220 intended participants) owing to slow recruitment, proposed as secondary to both a 
reduced number of PCVCs inserted compared with the number expected and identification of ineligible patients among those who had a PCVC in situ. Investigators reported a significant reduction in CLABSI in the intervention group on interim analysis utilising the $\mathrm{Chi}^{2}$ test, so the trial was ceased. Inclusion in the intervention group of an excess of male infants (66\% vs $44 \%, \mathrm{P}=0.05)$ and infants with necrotising enterocolitis $(21 \%$ vs $7 \%, P=0.06)$ may reflect an inadequate randomisation procedure. It is of note that the incidence of necrotising enterocolitis is high in the intervention group, as patients in this group are more likely to have received antibiotics during the time preceding removal of the CVC.

\section{Effects of interventions}

See: Summary of findings for the main comparison Antibiotics on removal of central venous catheter compared with no antibiotics

\section{Comparison 1: Cephazolin vs no cephazolin}

See Summary of findings for the main comparison.

\section{Primary outcomes (outcome 1.1)}

Data show no statistically significant difference in late-onset blood stream infection after removal of CVC in either group $10 \%$ in intervention group vs $11 \%$ in control group; risk ratio (RR) $0.09,95 \%$ confidence interval $(\mathrm{Cl}) 0.01$ to 1.60 ; risk difference (RD) $-0.11,95 \%$ $\mathrm{Cl}-0.21$ to -0.01 ; Figure 3 ). We downgraded the quality of evidence to low owing to high risk of bias and imprecision. Investigators reported no mortality in either group.

Figure 3. Forest plot of comparison: 1 Treatment with antibiotics versus no antibiotics, outcome: 1.1 Late-onset blood steam infection within 48 hours of CVC removal.

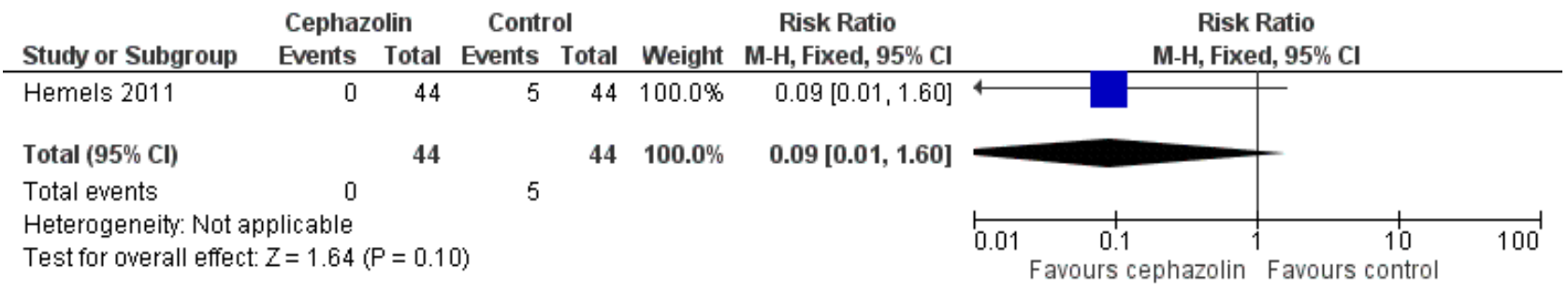

\section{Secondary outcomes}

Data show no significant difference in CLABSI within 48 hours of catheter removal $(0 \%$ in the intervention group vs $11 \%$ in the control group; RR $0.09,95 \% \mathrm{Cl} 0.01$ to $1.60 ; \mathrm{RD}-0.11,95 \% \mathrm{Cl}-0.21$ to -0.01; Figure 4) nor in blood stream infection with Gram-positive organisms $(0 \%$ in the intervention group vs $11 \%$ in the control group; RR $0.09,95 \% \mathrm{Cl} 0.01$ to 1.60 ; RD $-0.11,95 \% \mathrm{Cl}-0.21$ to -0.01 ; Figure 5 ) or clinical sepsis ( $0 \%$ in the intervention group vs $2 \%$ in the control group; RR 0.33, 95\% Cl 0.01 to 7.97 ; Figure 6). Duration of ventilation in days (median 0 (range 0 to 23 ) vs 0 (range 0 to 13); $P=0.73$ ) and duration of hospital stay in days (median 19 (range 8 to 106 ) vs median 21 (range 7 to 73 ); $P=0.66$ ) were not reported as significantly different in the study. Re-analysis of these continuous data required mean and standard deviation values. We contacted trial authors to request this information, but they did not reply. Investigators did not report other secondary outcome measures.

Figure 4. Forest plot of comparison: 1 Cephazolin compared with no cephazolin, outcome: 1.2 CLABSI.

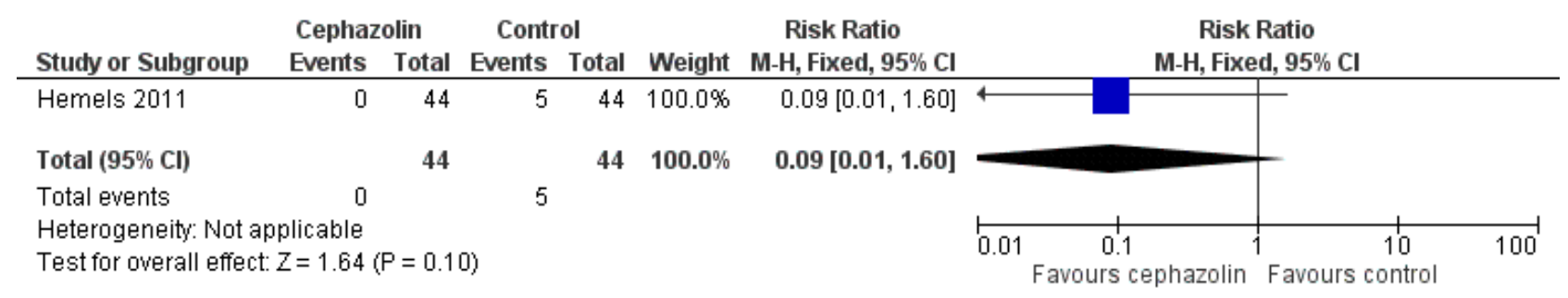


Figure 5. Forest plot of comparison: 1 Cephazolin compared with no cephazolin, outcome: 1.3 Gram-positive blood stream infection.

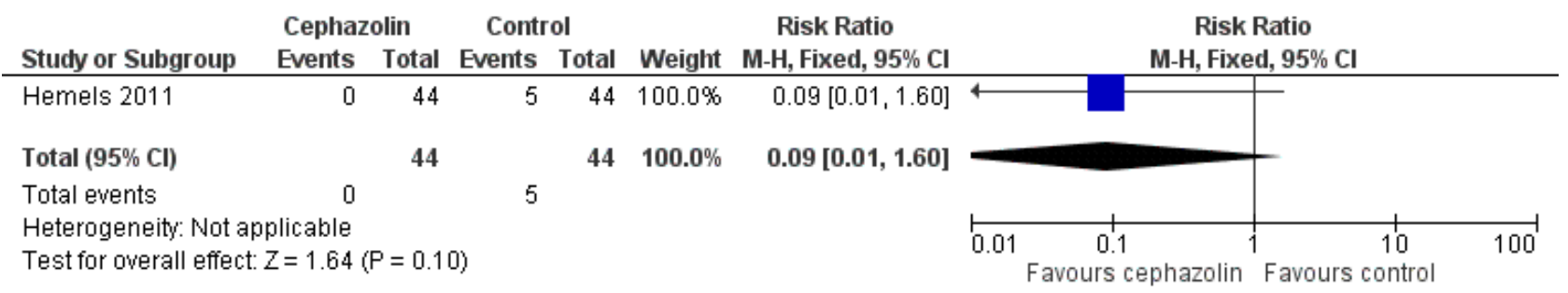

Figure 6. Forest plot of comparison: 1 Cephazolin compared with no cephazolin, outcome: 1.4 Clinical sepsis.

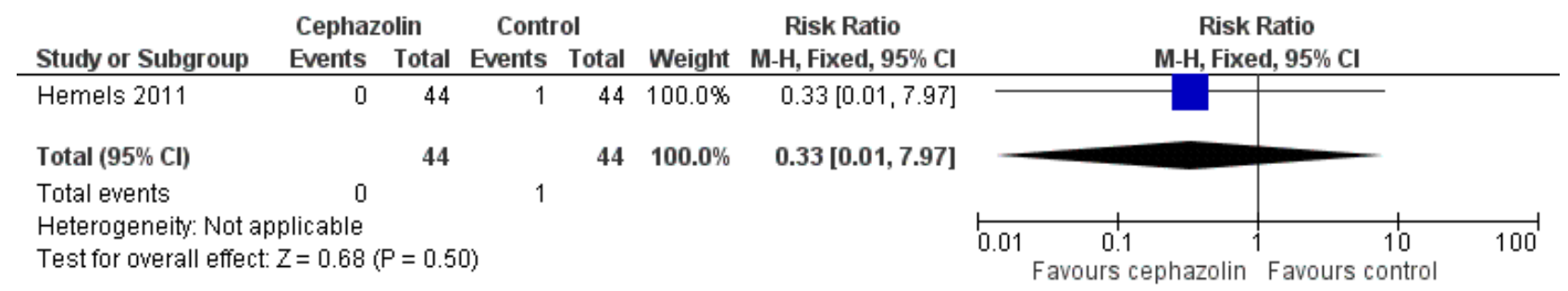

\section{Subgroup analyses}

We planned but did not run the following analyses, as we identified only one trial, which reported the results provided above.

- Term ( $\geq 37$ weeks' gestation) versus preterm (< 37 weeks' gestation) infants: All infants in Hemels 2011 were at less than 37 weeks' gestational age.

- Very low birth weight (<1500 grams) versus birth weight $\geq 1500$ grams: Hemels 2011 enrolled infants at less than 37 weeks' gestation. Birth weight was not significantly different between groups (median 1200 grams in the intervention group (range 750 to 3240 grams) vs 1170 grams in the control group (range 660 to 2390); $P=0.11$ ).

- Low- and middle-income settings versus high-income settings as defined by the World Bank (World Bank Data Resource 2015). The single included study was performed in a high-income, highresource setting.

- Type of antibiotic: broad spectrum (defined as an antibiotic with activity against multiple organisms) versus narrow spectrum (defined as an antibiotic primarily aimed at a specific organism): Hemels 2011 considered use of a single broad-spectrum antibiotic (cephazolin) versus no antibiotics.

- Type of catheter: single-lumen versus multiple-lumen, centrally inserted catheters versus peripherally inserted central venous catheters versus umbilical catheters: Hemels 2011 studied peripherally inserted central venous catheters only and did not document whether catheters were single or multiple lumen.

\section{DISCUSSION}

\section{Summary of main results}

We identified a single small randomised controlled trial that we found eligible for this review. The study was small, limiting its power to detect uncommon yet clinically meaningful outcomes such as central line-associated blood stream infection (CLABSI). We judged this trial to be of low quality owing to high risk of bias and imprecision. Cefazolin at the time of percutaneous central venous catheter (PCVC) removal did not statistically significantly alter any of the prespecified outcomes.

\section{Overall completeness and applicability of evidence}

This study is underpowered to permit clinically meaningful practice recommendations. The study's power was calculated upon a very high CLABSI rate (18.1/1000 line days) not commonly seen in neonatal intensive care units (NICUs) in resource-rich countries. In the context of much lower CLABSI rates, it seems that antibiotics at central venous catheter (CVC) removal as a sole intervention would require an unacceptably high number needed to treat to prevent one CLABSI, while exposing many infants to unnecessary antibiotics.

\section{Quality of the evidence}

We judged this single study to be of low quality (Summary of findings for the main comparison). The study was stopped early when only $40 \%$ of planned infants were recruited; it was unblinded, and study authors described unclear randomisation and allocation procedures. The study was underpowered to detect any meaningful clinical outcomes.

\section{Potential biases in the review process}

We encountered one challenge surrounding outcome definitions. Our primary outcome was late-onset sepsis after CVC removal, with clarification of timing of sepsis as a secondary outcome. The primary outcome of the single included study was late-onset sepsis within 48 hours of removal of CVC, which we discerned as included in this review's primary outcome, as it fit the definition as specified under Types of outcome measures. We obtained no further data from this study nor from other studies regarding lateonset sepsis at any time after CVC removal, which indicates that primary and secondary outcome data in this review are identical. 
This appears to be unlikely to affect review outcomes. This review shows no departure from the protocol. The literature search was extensive, and review authors independently assessed trial eligibility and quality and reached agreement through consensus. We are unaware of any other potential bias in this review, and review authors have reported no conflicts of interest.

\section{Agreements and disagreements with other studies or reviews}

Conflicting evidence surrounds both timing of infection related to CVC removal and use of antibiotics at the time of removal. The conclusion of this analysis contrasts with the conclusion of Hemels 2011, which interpreted study data as showing a significant reduction in PCVC removal-related CLABSI (5/44 (11\%) vs 0/44 (0\%), $P=0.02)$ after administration of cephazolin at the time of removal. However, data were analysed in a $\mathrm{Chi}^{2}$ test, whereas statistical convention would usually dictate use of Fisher's exact test for any cells with values less than five. With Fisher's exact test, $P=0.06$. A previous retrospective review of 345 PCVC by the same authors found clustering of CLABSI within 72 hours of removal and a sevenfold decrease in infection among infants who received antibiotics at the time of removal (van den Hoogen 2008). CLABSI within 72 hours of removal of CVC was significantly more frequent in infants of lower birth weight and gestational age. Lindquist 2016 studied removal of 372 umbilical CVCs in a retrospective cohort analysis and noted a significant reduction in CLABSI within 72 hours of CVC removal among 146 infants weighing $<1500$ grams when antibiotics were continued after removal rather than stopped at the time of removal $(8.3 \%$ vs $30 \% ; P<0.001)$. In contrast, a retrospective review of 101 PCVCs showed no increase in CLABSI rate after PCVC removal compared with CLABSI rate while a PCVC remained in situ; review authors concluded that antibiotics provided no benefit at the time of removal (Brooker 2007). The largest study to date - Casner 2014 - analysed 1002 PCVCs in 856 infants. Trial authors documented no difference in prevalence of CLABSI, culture-negative sepsis, or sepsis evaluation before and after removal of PCVCs throughout the entire cohort. However, in the subgroup of PCVCs that had not been used for antibiotic delivery, investigators did note a 3.8-fold increase in the odds ratio for culture-negative sepsis following PCVC removal; for very low birth weight infants within this subgroup, the odds ratio was increased 6.3-fold. Researchers also saw a significant increase in culture-negative sepsis, sepsis evaluations, and apnoeas and bradycardias after removal of PCVC if the catheter had a dwell time longer than 10 days. It may be that some cases of 'sepsis' documented in these cohorts are a manifestation of an inflammatory response to disruption of the catheter biofilm rather than reflecting a septic shower of microbes, and that approaches other than antibiotics are necessary to minimise formation or colonisation of the biofilm.

It is noteworthy that in the retrospective observational study in which antibiotics were seen to reduce CVC removal-related CLABSI, the overall CLABSI rate was high, at 18.1/1000 line days (van den Hoogen 2008). Most NICUs in resource-rich countries report rates much lower than this, and the latest rates reported by the American National Healthcare Safety Network show 1.13/1000 central line days in the NICU (Dudeck 2015). Rates continue to decline with focussed bundles of central line insertion and maintenance interventions with emphasis upon timely audit and feedback (Bizzarro 2010; Bowen 2017; Schulman 2011). CVCs now are used less often and are removed earlier, resulting in lower central line usage and lower CLABSI rates (Dudeck 2015). Longer dwell times appear to be related to risk of CLABSI (Greenhalgh 2014; Milstone 2013). Future research may be best directed towards determining which infants need a CVC and how long it should remain in situ rather than use of prophylactic antibiotics.

Antibiotic resistance is emerging as a globally important and urgent issue, and reducing antibiotic exposure is a priority. The effects of prophylactic antibiotics during the life of the catheter or upon removal on total antibiotic exposure and resistance patterns have not been explored in the literature. It is possible that one dose of antibiotic given upon removal of a CVC may prevent a subsequent CLABSI, thus reducing total antibiotic duration by avoiding a prolonged treatment course, but both background incidence of CLABSI and effectiveness of treatment would have to be high to justify exposing many infants to unnecessary antibiotics. For example, Hemels 2011 gave nine infants two doses of antibiotics to prevent one CLABSI and provided a subsequent prolonged course of antibiotics to one infant. With a current background rate of 1 to 3 CLABSI per 1000 line days, the number of infants exposed to prophylactic antibiotics to avoid one CLABSI would be much higher, and consequently a reduction in CLABSI of at least $50 \%$ would be needed to justify antibiotic use upon removal of all CVCs. This seems improbable; thus a policy of giving antibiotics at removal of all CVCs appears unlikely to impact CLABSI rates further in the current era of low and declining prevalence of CLABSI.

However, the impact of CLABSI at an individual level remains high. It has been suggested that CLABSI within 48 to 72 hours of removal of a CVC may cause complications in smaller and more preterm infants, and in particular those infants who had CVC present of long dwell time and which had not been previously used to deliver antibiotics. Future research may be best directed towards use of antibiotics at removal in these infants. Clarification of antibiotic choice and regimen would be required, and effects upon total antibiotic duration and resistance patterns investigated, as well as potential effects upon gut microbial diversity. Neonatal sepsis research should include short-term efficacy and safety data, as well as clinically important core outcomes, in addition to long-term child health outcomes. Shortterm outcomes should utilise a neonatal core outcome set to facilitate reporting and translation of research into clinical practice, and should aim to link emerging basic science data to meaningful clinical outcomes, such as the impact of antibiotic exposure, early-life microbial colonisation patterns, and core neonatal outcomes (Webbe 2017). Longer-term outcomes should include child health outcomes including impact upon atopic disease and developmental outcomes. Investigations of meaningful but uncommon long-term outcomes with adequate power will require large numbers of infants and will be best conducted across neonatal networks. Quality improvement research should be designed as well as other types of research and should utilise standardised frameworks for interventions (Institute for Healthcare Improvement 2017), along with a robust but pragmatic research design and inclusion of core outcomes. Bundles used to prevent CLABSI should be adapted and made appropriate for the healthcare setting, but national evidence-based best practice guidelines are available (e.g. Ontario 2015). Novel research designs such as cluster-randomised cross-over trials or stepped-wedge clusterrandomised trials may be best suited to assess the impact of routine NICU interventions on low prevalence outcomes (Bellomo 2013). 


\section{AUTHORS' CONCLUSIONS}

\section{Implications for practice}

Evidence from randomised controlled trials is inadequate for assessment of the efficacy and safety of antibiotics at the time of removal of PCVCs from newborn infants.

\section{Implications for research}

Future research should be directed towards targeting antibiotics on removal of PCVCs for those at greatest risk of complications from late-onset sepsis, such as very low birth weight infants, those with long CVC dwell time, and those not recently exposed to antibiotics. Antibiotic choice and regimen require clarification, as do impact upon antibiotic use and resistance patterns. Outcomes of sepsis research should address not only short-term efficacy and safety, but also meaningful medium-term and longer-term core outcomes such as childhood health and neurodevelopmental outcomes. These are best investigated as part of a bundle of quality improvement care interventions; these trials would require large numbers of participants and multi-centre co-operation within neonatal networks.

\section{A C K N O WLE D G E MENTS}

None. 


\section{REFERE N CES}

\section{References to studies included in this review}

\section{Hemels 2011 \{published data only\}}

Hemels MA, van den Hoogen A, Verboon-Maciolek MA, Fleer A, Krediet TG. Prevention of neonatal late-onset sepsis associated with the removal of percutaneously inserted central venous catheters in preterm infants. Pediatric Critical Care Medicine 2011;12(4):445-8. [DOI: 10.1097/PCC.0b013e3182070f5d; PUBMED: 21263371

\section{References to studies excluded from this review}

\section{Harms 1995 \{published data only\}}

Harms K, Herting E, Kron M, Schiffmann H, Schulz-Ehlbeck H. Randomized, controlled trial of amoxicillin prophylaxis for prevention of catheter-related infections in newborn infants with central venous silicone elastomer catheters. Journal of Pediatrics 1995;127(4):615-9. [PUBMED: 7562288]

\section{Lindquist 2016 \{published data only\}}

Lindquist S, Hentz E, Tessin I, Elfvin A. Very low birthweight infants face an increased risk of bloodstream infections following the removal of umbilical catheters. Acta Paediatrica 2016;105(4):391-6. [DOI: 10.1111/apa.13240; PUBMED: 26461802]

\section{van den Hoogen 2008 \{published data only\}}

van den Hoogen A, Brouwer MJ, Gerards LJ, Fleer A, Krediet TG. Removal of percutaneously inserted central venous catheters in neonates is associated with the occurrence of sepsis. Acta Paediatrica 2008;97(9):1250-2. [DOI: 10.1111/ j.1651-2227.2008.00864.x; PUBMED: 18477060

\section{Additional references}

\section{Ainsworth 2015}

Ainsworth SB, McGuire W. Percutaneous central venous catheters versus peripheral cannulae for delivery of parenteral nutrition in neonates. Cochrane Database of Systematic Reviews 2015, Issue 10. [DOI: 10.1002/14651858.CD004219.pub4]

\section{Allegranzi 2011}

Allegranzi B, Bagheri Nejad S, Combescure C, Graafmans W, Attar H, Donaldson L, et al. Burden of endemic health-careassociated infection in developing countries: systematic review and meta-analysis. Lancet 2011;377(9761):228-41. [DOI: 10.1016/S0140-6736(10)61458-4; PUBMED: 21146207]

\section{Alshaikh 2014}

Alshaikh B, Yee W, Lodha A, Henderson E, Yusuf K, Sauve R. Coagulase-negative staphylococcus sepsis in preterm infants and long-term neurodevelopmental outcome. Journal of Perinatology 2014;34(2):125-9. [DOI: 10.1038/jp.2013.155; PUBMED: 24355942]

\section{Bellomo 2013}

Bellomo R, Forbes A, Akram M, Bailey M, Pilcher DV, Cooper DJ. Why we must cluster and cross over. Critical Care \& Resuscitation 2013;15(3):155-7.

\section{Bizzarro 2010}

Bizzarro MJ, Sabo B, Noonan M, Bonfiglio MP, Northrup V, Diefenbach K, Central Venous Catheter Initiative Committee. A quality improvement initiative to reduce central line-associated bloodstream infections in a neonatal intensive care unit. Infection Control and Hospital Epidemiology 2010;31(3):241-8.

\section{Bowen 2017}

Bowen JR, Callander I, Richards R, Lindrea KB, Sepsis Prevention in NICUs Group. Decreasing infection in neonatal intensive care units through quality improvement. Archives of Disease in Childhood. Fetal and Neonatal Edition 2017;102(1):F51-7. [DOI: 10.1136/archdischild-2015-310165; PUBMED: 27142638]

\section{Brooker 2007}

Brooker RW, Keenan WJ. Catheter related bloodstream infection following PICC removal in preterm infants. Journal of Perinatology 2007;27(3):171-4. [DOI: 10.1038/sj.jp.7211655; PUBMED: 17314985]

\section{Canadian Neonatal Network 2015}

Canadian Neonatal Network. The Canadian Neonatal Network Annual Report 2015. http:// www.canadianneonatalnetwork.org/Portal/LinkClick.aspx? fileticket $=9 \mathrm{~K} 3 \mathrm{crPtfgQs} \% 3 \mathrm{~d} \&$ tabid=39 (accessed 10 August 2017).

\section{Casner 2014}

Casner M, Hoesli SJ, Slaughter JC, Hill M, Weitkamp JH. Incidence of catheter-related bloodstream infections in neonates following removal of peripherally inserted central venous catheters. Pediatric Critical Care Medicine 2014;15(1):42-8.

\section{Dudeck 2015}

Dudeck MA, Edwards JR, Allen-Bridson K, Gross C, Malpiedi PJ, Peterson KD, et al. National Healthcare Safety Network Report, Data Summary for 2013, Device-Associated Module. American Journal of Infection Control 2015;43(3):206-21. [DOI: 10.1016/ j.ajic.2014.11.014; PUBMED: 25575913]

\section{GRADEpro GDT [Computer program]}

GRADE Working Group, McMaster University (developed by Evidence Prime). GRADEpro GDT. Version accessed 6 April 2017. Hamilton (ON): GRADE Working Group, McMaster University (developed by Evidence Prime), 2015. Available from gradepro.org.

\section{Gray 1995}

Gray JE, Richardson DK, McCormick MC, Goldmann DA. Coagulase-negative staphylococcal bacteremia among very low birth weight infants: relation to admission illness severity, 
resource use, and outcome. Pediatrics 1995;95(2):225-30. [PUBMED: 7838640]

\section{Greenhalgh 2014}

Greenhalgh M, Gordon A. An audit of central line use and associated blood stream infections in a tertiary NICU. Journal of Paediatrics and Child Health. 2014; Vol. 50:61.

\section{Higgins 2011}

Higgins A, Green S (editors). Cochrane Handbook for Systematic Reviews of Interventions Version 5.1.0 (updated March 2011). The Cochrane Collaboration, 2011. Available from www.cochrane-handbook.org.

\section{Institute for Healthcare Improvement 2017}

Institute for Healthcare Improvement. How to improve. http:// www.ihi.org/resources/Pages/Howtolmprove/default.aspx. Accessed 6 April 20172017

\section{Isaacs 2003}

Isaacs D, Australasian Study Group for Neonatal Infections. A ten year, multicentre study of coagulase negative staphylococcal infections in Australasian neonatal units. Archives of Disease in Childhood. Fetal and Neonatal Edition 2003;88(2):F89-93. [PUBMED: 12598493]

\section{Janes 2000}

Janes M, Kalyn A, Pinelli J, Paes B. A randomized trial comparing peripherally inserted central venous catheters and peripheral intravenous catheters in infants with very low birth weight. Journal of Pediatric Surgery 2000;35(7):1040-4. [DOI: 10.1053/ jpsu.2000.7767; PUBMED: 10917292]

\section{Jardine 2008}

Jardine LA, Inglis GD, Davies MW. Prophylactic systemic antibiotics to reduce morbidity and mortality in neonates with central venous catheters. Cochrane Database of Systematic Reviews 2008, Issue 1. [DOI: 10.1002/14651858.CD006179.pub2]

\section{Karlowicz 2000}

Karlowicz MG, Buescher ES, Surka AE. Fulminant late-onset sepsis in a neonatal intensive care unit, 1988-1997, and the impact of avoiding empiric vancomycin therapy. Pediatrics 2000;106(6):1387-90. [PUBMED: 11099593]

\section{Makhoul 2005}

Makhoul IR, Sujov P, Smolkin T, Lusky A, Reichman B, Israel Neonatal Network. Pathogen-specific early mortality in very low birth weight infants with late-onset sepsis: a national survey. Clinical Infectious Diseases 2005;40(2):218-24. [DOI: 10.1086/426444; PUBMED: 15655738]

\section{McMullan 2016}

McMullan R, Gordon A. Impact of a central line infection prevention bundle in newborn infants. Infection Control and Hospital Epidemiology 2016;37(9):1029-36. [DOI: 10.1017/ ice.2016.127; PUBMED: 27289400]

\section{Mermel 2011}

Mermel LA. What is the predominant source of intravascular catheter infections?. Clinical Infectious Diseases

2011;52(2):211-2. [DOI: 10.1093/cid/ciq108; PUBMED: 21288845]

\section{Milstone 2013}

Milstone AM, Reich NG, Advani S, Yuan G, Bryant K, Coffin SE, et al. Catheter dwell time and CLABSIs in neonates with PICCs: a multicenter cohort study. Pediatrics 2013;132(6):e1609-15. [DOI: 10.1542/peds.2013-1645; PUBMED: 24218474]

\section{O'Grady 2011}

O'Grady NP, Alexander M, Burns LA, Dellinger EP, Garland J, Heard SO, et al. Healthcare Infection Control Practices Advisory Committee. Guidelines for the prevention of intravascular catheter-related infections. American Journal of Infection Control 2011;39(4 Suppl 1):S1-34. [DOI: 10.1016/ j.ajic.2011.01.003; PUBMED: 21511081]

\section{Ontario 2015}

Ontario Agency for Health Protection and Promotion Provincial Infectious Diseases Advisory Committee. Best practices for infection prevention and control in perinatology. https://www.publichealthontario.ca/en/BrowseByTopic/ InfectiousDiseases/PIDAC/Pages/PIDAC_Documents.aspx. Accessed 6 April 2017. Toronto, Ontario: Queen's Printer for Ontario, 2015.

\section{Pronovost 2006}

Pronovost P, Needham D, Berenholtz S, Sinopoli D, Chu H, Cosgrove $S$, et al. An intervention to decrease catheter-related bloodstream infections in the ICU. New England Journal of Medicine 2006;355(26):2725-32. [DOI: 10.1056/NEJMoa061115; PUBMED: 17192537$]$

\section{RCPCH 2016}

Royal College of Paediatrics and Child Health. National Neonatal Audit Programme: 2016 Annual Report on 2015 Data. http://www.rcpch.ac.uk/system/files/protected/page/NNAP \%202016\%20Annual\%20Report\%20on\%202015\%20data\%20\%20For\%20NNAP\%20website.pdf (accessed 10 August 2017).

\section{Review Manager 2014 [Computer program]}

Nordic Cochrane Centre, The Cochrane Collaboration. Review Manager 5 (RevMan 5). Version 5.3. Copenhagen: Nordic Cochrane Centre, The Cochrane Collaboration, 2014.

\section{Rosenthal 2009}

Rosenthal VD. Central line-associated bloodstream infections in limited-resource countries: a review of the literature. Clinical Infectious Diseases 2009;49(12):1899-907. [DOI: 10.1086/648439; PUBMED: 19911941]

\section{Rosenthal 2010}

Rosenthal VD, Maki DG, Jamulitrat S, Medeiros EA, Todi SK, Gomez DY, et al. INICC Members. International Nosocomial Infection Control Consortium (INICC) report, data summary for 2003-2008, issued June 2009. American Journal of Infection Control 2010;38(2):95-104.e2. [DOI: 10.1016/j.ajic.2009.12.004; PUBMED: 20176284] 


\section{Salzman 1993}

Salzman MB, Isenberg HD, Shapiro JF, Lipsitz PJ, Rubin LG. A prospective study of the catheter hub as the portal of entry for microorganisms causing catheter-related sepsis in neonates. Journal of Infectious Diseases 1993;167(2):487-90. [PUBMED: 8421188]

\section{Salzman 1995}

Salzman MB, Rubin LG. Intravenous catheter-related infections. Advances in Pediatric Infectious Diseases 1995;10:337-68. [PUBMED: 7718211]

\section{Schlapbach 2011}

Schlapbach LJ, Aebischer M, Adams M, Natalucci G, Bonhoeffer J, Latzin P, et al. Swiss Neonatal Network and Follow-Up Group. Impact of sepsis on neurodevelopmental outcome in a Swiss National Cohort of extremely premature infants. Pediatrics 2011;128(2):e348-57. [DOI: 10.1542/ peds.2010-3338; PUBMED: 21768312]

\section{Schulman 2011}

Schulman J, Stricof R, Stevens TP, Horgan M, Gase K, Holzman IR, et al. New York State Regional Perinatal Care Centers. Statewide NICU central-line-associated bloodstream infection rates decline after bundles and checklists. Pediatrics 2011;127(3):436-44. [DOI: 10.1542/peds.2010-2873; PUBMED: 21339265]

\section{Schünemann 2013}

Schünemann H, Brożek J, Guyatt G, Oxman A, editors. GRADE Working Group. GRADE handbook for grading quality of

\section{CHARACTERISTICS OF STUDIES}

\section{Characteristics of included studies [ordered by study ID]}

evidence and strength of recommendations. Available from www.guidelinedevelopment.org/handbook Updated October 2013.

\section{Stoll 2002}

Stoll BJ, Hansen N, Fanaroff AA, Wright LL, Carlo WA, Ehrenkranz RA, et al. Late-onset sepsis in very low birth weight neonates: the experience of the NICHD Neonatal Research Network. Pediatrics 2002;110(2 Pt 1):285-91. [PUBMED: 12165580]

\section{Stoll 2004}

Stoll BJ, Hansen NI, Adams-Chapman I, Fanaroff AA, Hintz SR, Vohr B, et al. National Institute of Child Health and Human Development Neonatal Research Network. Neurodevelopmental and growth impairment among extremely low-birth-weight infants with neonatal infection. JAMA 2004;292(19):2357-65. [DOI: 10.1001/jama.292.19.2357; PUBMED: 15547163$]$

\section{The Joint Commission 2012}

The Joint Commission. Preventing central line-associated bloodstream infections: a global challenge, a global perspective. http://www.jointcommission.org/assets/1/18/ clabsi_monograph.pdf (accessed 4 December 2014).

\section{Webbe 2017}

Webbe J, Brunton G, Ali S, Duffy J, Modi N, Gale C. Developing, implementing and disseminating a core outcome set for neonatal medicine. BMJ Paediatrics Open 2017;1(1):1-5.

\section{Hemels 2011}

\begin{tabular}{|c|c|}
\hline Methods & Prospective, open, randomised, controlled study \\
\hline \multirow[t]{4}{*}{ Participants } & $\begin{array}{l}\text { Inclusion criteria: Infants at }<37 \text { weeks' gestation admitted to a single neonatal intensive care unit with } \\
\text { an indwelling percutaneously inserted central venous catheter }\end{array}$ \\
\hline & $\begin{array}{l}\text { Exclusion criteria: clinical signs of sepsis or phlebitis at the insertion site and subsequent removal of } \\
\text { the PCVC, antibiotic use } 24 \text { hours before removal of the PCVC, no informed consent, transfer to another } \\
\text { hospital, death before removal of the PCVC }\end{array}$ \\
\hline & $\begin{array}{l}\text { Control group: } N=44 . \text { Median gestational age } 30 \text { weeks (range } 25 \text { to 35), median birth weight } 1170 \\
\text { grams (range } 660 \text { to } 2390 \text { grams), } 46 \% \text { male infants }\end{array}$ \\
\hline & $\begin{array}{l}\text { Intervention group: } N=44 \text {. Median gestational age } 29 \text { weeks (range } 25 \text { to } 36 \text { ), median birth weight } 1200 \\
\text { grams (range } 750 \text { to } 3240 \text { grams), } 66 \% \text { male infants }\end{array}$ \\
\hline
\end{tabular}

Interventions

Two doses of intravenous cephazolin at $50 \mathrm{mg} / \mathrm{kg}$ dose 1 hour before and 12 hours after removal of the catheter

Outcomes

Primary outcome: sepsis within 48 hours of catheter removal (sepsis defined as clinical signs consistent with sepsis, positive blood culture, and laboratory abnormalities)

Secondary outcome: clinical signs of sepsis after catheter removal; CRP values at 24, 48, and 72 hours after removal; hospitalisation days; ventilation days; mortality 
Hemels 2011 (Continued)

Notes

\section{Risk of bias}

\begin{tabular}{|c|c|c|}
\hline Bias & Authors' judgement & Support for judgement \\
\hline $\begin{array}{l}\text { Random sequence genera- } \\
\text { tion (selection bias) }\end{array}$ & Unclear risk & Randomisation procedure was not reported. \\
\hline $\begin{array}{l}\text { Allocation concealment } \\
\text { (selection bias) }\end{array}$ & Unclear risk & Allocation procedure was not reported. \\
\hline $\begin{array}{l}\text { Blinding of participants } \\
\text { and personnel (perfor- } \\
\text { mance bias) } \\
\text { All outcomes }\end{array}$ & High risk & No blinding or placebo was utilised. \\
\hline $\begin{array}{l}\text { Blinding of outcome as- } \\
\text { sessment (detection bias) } \\
\text { All outcomes }\end{array}$ & Unclear risk & Blinding was not described. \\
\hline $\begin{array}{l}\text { Incomplete outcome data } \\
\text { (attrition bias) } \\
\text { All outcomes }\end{array}$ & Low risk & Complete data were available for all patients entering the study. \\
\hline $\begin{array}{l}\text { Selective reporting (re- } \\
\text { porting bias) }\end{array}$ & Low risk & $\begin{array}{l}\text { Mortality data were not published although this was a prespecified outcome. } \\
\text { We resolved this matter on contact with trial authors. }\end{array}$ \\
\hline Other bias & High risk & $\begin{array}{l}\text { We judged this trial to be at high risk of bias, as the trial was stopped early } \\
\text { when } 88 \text { of the planned } 220 \text { participants had been enrolled, and trial authors } \\
\text { reported statistically significant differences upon analysis based on a } \mathrm{Chi}^{2} \text { test. }\end{array}$ \\
\hline
\end{tabular}

CRP: C-reactive protein.

PCVC: percutaneous central venous catheter.

Characteristics of excluded studies [ordered by study ID]

\begin{tabular}{ll}
\hline Study & Reason for exclusion \\
\hline Harms 1995 & $\begin{array}{l}\text { Randomised controlled trial of prophylactic antibiotics for duration of the central venous catheter } \\
\text { (CVC), not solely at removal }\end{array}$ \\
\hline Lindquist 2016 & Retrospective cohort analysis \\
\hline van den Hoogen 2008 & Retrospective cohort analysis \\
\hline
\end{tabular}

\section{DATA AND ANALYSES}


Comparison 1. Cephazolin compared to no cephazolin

\begin{tabular}{lllll}
\hline Outcome or subgroup title & No. of studies & $\begin{array}{l}\text { No. of partici- } \\
\text { pants }\end{array}$ & Statistical method & Effect size \\
\hline $\begin{array}{l}1 \text { Late-onset blood steam in- } \\
\text { fection }\end{array}$ & 1 & 88 & Risk Ratio (M-H, Fixed, 95\% Cl) & $0.09[0.01,1.60]$ \\
\hline 2 CLABSI & 1 & 88 & Risk Ratio (M-H, Fixed, 95\% Cl) & $0.09[0.01,1.60]$ \\
\hline $\begin{array}{l}3 \text { Gram-positive blood stream } \\
\text { infection }\end{array}$ & 1 & 88 & Risk Ratio (M-H, Fixed, 95\% Cl) & $0.09[0.01,1.60]$ \\
\hline 4 Clinical sepsis & 1 & 88 & Risk Ratio (M-H, Fixed, 95\% Cl) & $0.33[0.01,7.97]$ \\
\hline
\end{tabular}

Analysis 1.1. Comparison 1 Cephazolin compared to no cephazolin, Outcome 1 Late-onset blood steam infection.

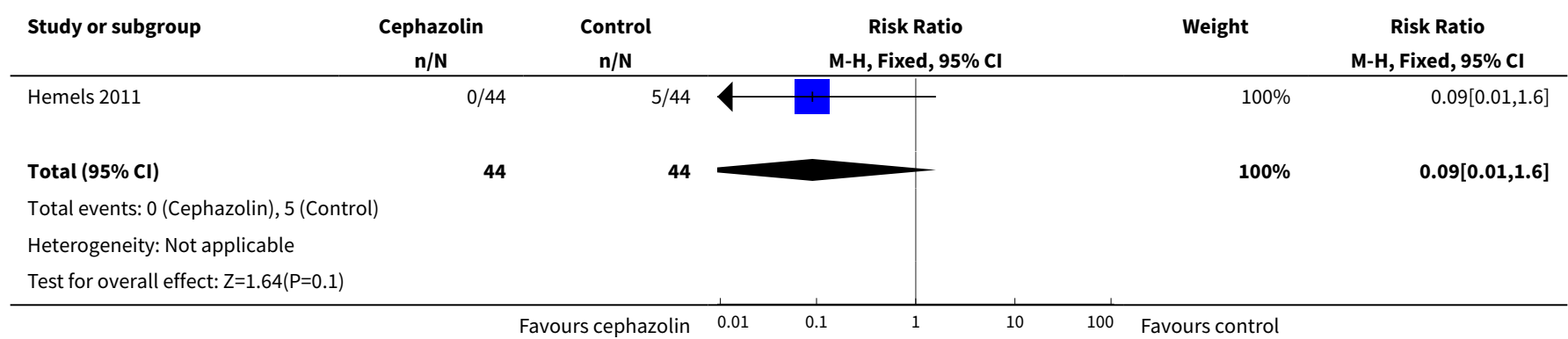

Analysis 1.2. Comparison 1 Cephazolin compared to no cephazolin, Outcome 2 CLABSI.

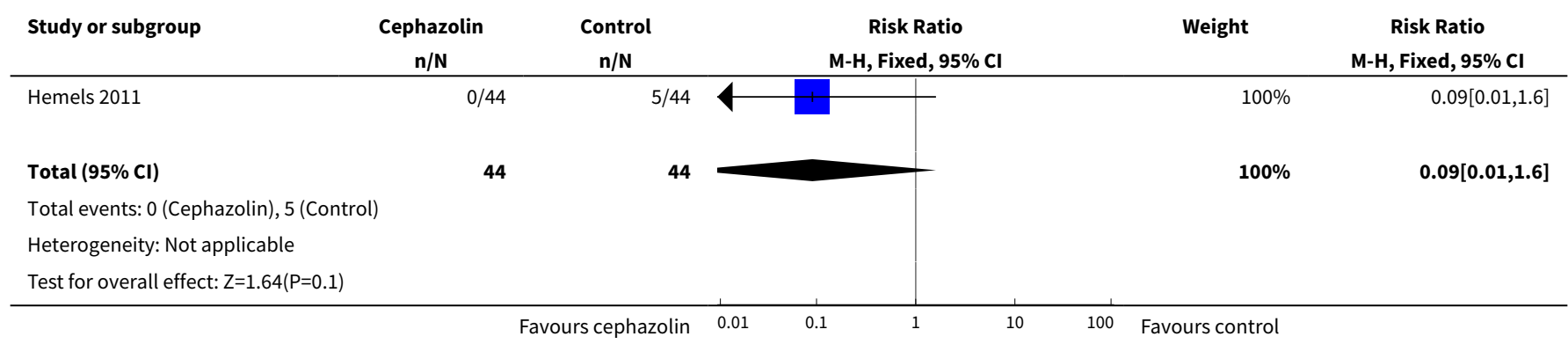

Analysis 1.3. Comparison 1 Cephazolin compared to no cephazolin, Outcome $3 \mathrm{Gram}$-positive blood stream infection.

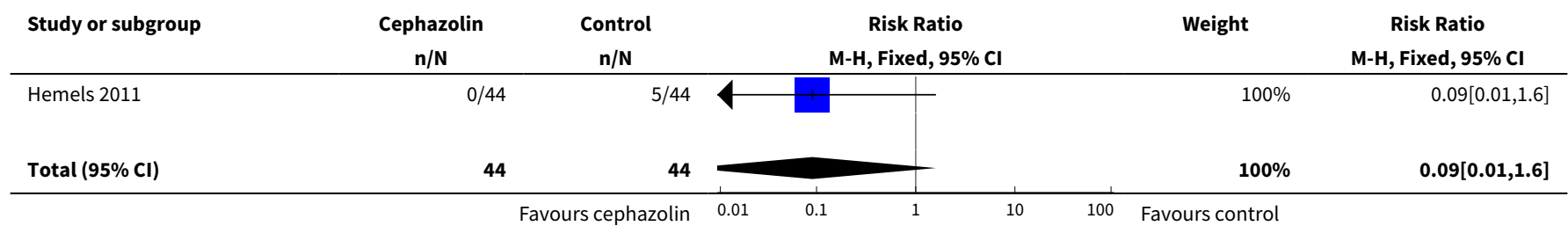




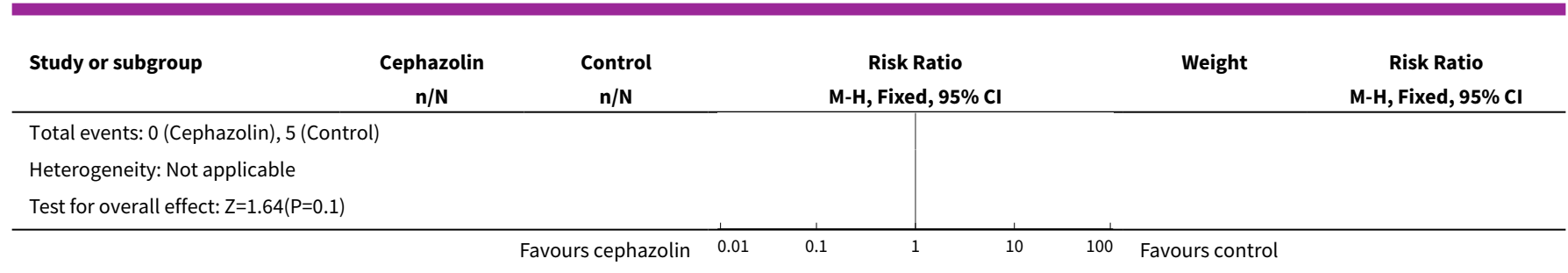

Analysis 1.4. Comparison 1 Cephazolin compared to no cephazolin, Outcome 4 Clinical sepsis.

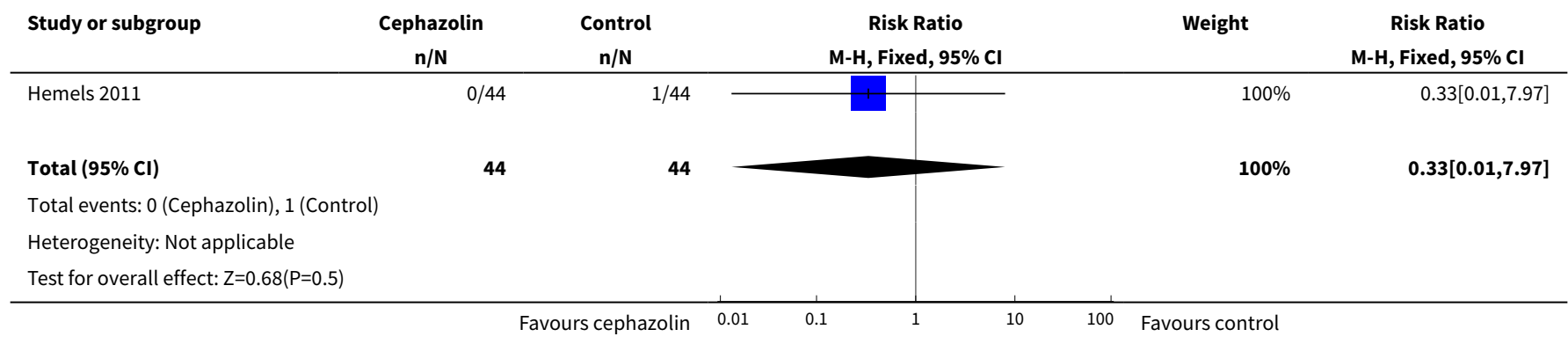

\section{APPENDICES}

\section{Appendix 1. Standard search methods}

PubMed: ((infant, newborn[MeSH] OR newborn OR neonate OR neonatal OR premature OR low birth weight OR VLBW OR LBW or infan* or neonat ${ }^{\star}$ ) AND (randomised controlled trial [pt] OR controlled clinical trial [pt] OR randomised [tiab] OR placebo [tiab] OR drug therapy [sh] OR randomly [tiab] OR trial [tiab] OR groups [tiab]) NOT (animals [mh] NOT humans [mh]))

Embase: (infant, newborn or newborn or neonate or neonatal or premature or very low birth weight or low birth weight or VLBW or LBW or Newborn or infan* or neonat*) AND (human not animal) AND (randomised controlled trial or controlled clinical trial or randomised or placebo or clinical trials as topic or randomly or trial or clinical trial)

CINAHL: (infant, newborn OR newborn OR neonate OR neonatal OR premature OR low birth weight OR VLBW OR LBW or Newborn or infan* or neonat ${ }^{\star}$ ) AND (randomised controlled trial OR controlled clinical trial OR randomised OR placebo OR clinical trials as topic OR randomly OR trial OR PT clinical trial)

Cochrane Library: (infant or newborn or neonate or neonatal or premature or preterm or very low birth weight or low birth weight or VLBW or LBW)

\section{Appendix 2. Risk of bias tool}

We used the standard methods of Cochrane and Cochrane Neonatal to assess the methodological quality (to meet the validity criteria) of trials. For each trial, we sought information regarding the method of randomisation and blinding and reporting of all outcomes of all infants enrolled in the trial. We assessed each criterion as having low, high, or unclear risk. Two review authors separately assessed each study. We resolved disagreements by discussion. We added this information to the 'Characteristics of included studies' table. We evaluated the following issues and entered our findings into the risk of bias table.

1. Sequence generation (checking for possible selection bias). Was the allocation sequence adequately generated?

For each included study, we categorised the method used to generate the allocation sequence as:

a. low risk (any truly random process, e.g. random number table; computer random number generator);

b. high risk (any non-random process, e.g. odd or even date of birth; hospital or clinic record number); or

c. unclear risk. 
2. Allocation concealment (checking for possible selection bias). Was allocation adequately concealed?

For each included study, we categorised the method used to conceal the allocation sequence as:

a. low risk (e.g. telephone or central randomization; consecutively numbered sealed opaque envelopes);

b. high risk (e.g. open random allocation; unsealed or non-opaque envelopes, alternation; date of birth); or

c. unclear risk.

3. Blinding of participants and personnel (checking for possible performance bias). Was knowledge of the allocated intervention adequately prevented during the study?

For each included study, we categorised the methods used to blind study participants and personnel from knowledge of which intervention a participant received. Blinding was assessed separately for different outcomes or classes of outcomes. We categorized the methods as:

a. low risk, high risk, or unclear risk for participants; and

b. low risk, high risk, or unclear risk for personnel.

4. Blinding of outcome assessment (checking for possible detection bias). Was knowledge of the allocated intervention adequately prevented at the time of outcome assessment?

For each included study, we categorised the methods used to blind outcome assessment. Blinding was assessed separately for different outcomes or classes of outcomes. We categorised the methods as:

a. low risk for outcome assessors;

b. high risk for outcome assessors; or

c. unclear risk for outcome assessors.

5. Incomplete outcome data (checking for possible attrition bias through withdrawals, dropouts, protocol deviations). Were incomplete outcome data adequately addressed?

For each included study and for each outcome, we described the completeness of data including attrition and exclusions from analysis. We noted whether attrition and exclusions were reported, numbers included in the analysis at each stage (compared with total randomised participants), reasons for attrition or exclusion when reported, and whether missing data were balanced across groups or were related to outcomes. When sufficient information was reported or was supplied by trial authors, we re-included missing data in our analyses. We categorised the methods as:

a. low risk (<20\% missing data);

b. high risk ( $\geq 20 \%$ missing data); or

c. unclear risk.

6. Selective reporting bias. Are reports of the study free of the suggestion of selective outcome reporting?

For each included study, we described how we investigated the possibility of selective outcome reporting bias and what we found. We assessed the methods as:

a. low risk (when it is clear that all of the study's prespecified outcomes and all expected outcomes of interest to the review have been reported);

b. high risk (when not all of the study's prespecified outcomes have been reported; one or more reported primary outcomes were not prespecified outcomes of interest and are reported incompletely and so cannot be used; or study fails to include results of a key outcome that would have been expected to have been reported); or

c. unclear risk.

7. Other sources of bias. Was the study apparently free of other problems that could put it at high risk of bias?

For each included study, we described any important concerns that we had about other possible sources of bias (e.g. whether a potential source of bias was related to the specific study design, whether the trial was stopped early owing to some data-dependent process). We assessed whether each study was free of other problems that could put it at risk of bias as: 
a. low risk;

b. high risk; or

c. unclear risk.

If needed, we explored the impact of the level of bias by performing sensitivity analyses.

\section{CONTRIBUTIONS OF AUTHORS}

Both RM and AG performed searches, assessed studies, extracted data, and wrote the review.

\section{DECLARATIONS OF INTEREST}

None.

\section{SOURCES OF SUPPORT}

\section{Internal sources}

- No sources of support supplied

\section{External sources}

- Eunice Kennedy Shriver National Institute of Child Health and Human Development, National Institutes of Health, Department of Health and Human Services, USA.

Editorial support for the Cochrane Neonatal Review Group has been funded with Federal funds from the Eunice Kennedy Shriver National Institute of Child Health and Human Development, National Institutes of Health, Department of Health and Human Services, USA, under Contract No. HHSN275201100016C.

- National Institution for Health Research, UK.

Editorial support for Cochrane Neonatal has been funded by a UK National Insititute of Health Reasearch Grant (NIHR) Cochrane Programme Grant (13/89/12). The views expressed in this publication are those of the review authors and are not necessarily those of the NHS, the NIHR, or the UK Department of Health.

\section{INDEX TERMS}

\section{Medical Subject Headings (MeSH)}

${ }^{\star}$ Device Removal; Anti-Bacterial Agents [ ${ }^{*}$ therapeutic use]; Catheter-Related Infections [etiology] [mortality] [ ${ }^{*}$ prevention \& control]; Cause of Death; Cefazolin [*therapeutic use]; Central Venous Catheters [ ${ }^{\star}$ adverse effects]; Infant Mortality; Sepsis [mortality] [*prevention \& control]

\section{MeSH check words}

Humans; Infant; Infant, Newborn 